\title{
Numerical investigation of FZ-growth of GaAs with encapsulant
}

\author{
Mingwei $\mathrm{Li}^{\mathrm{a}, *}$, Wenrui $\mathrm{Hu}{ }^{\mathrm{b}}$, Shuxian Chen ${ }^{\mathrm{a}}$ \\ ${ }^{a}$ Institute of Power Engineering, Chongqing University, Chongqing 400044, China \\ ${ }^{\mathrm{b}}$ Institute of Mechanics, CAS, Beijing 100083, China
}

Received 21 November 2003; received in revised form 15 March 2004

\begin{abstract}
Numerical simulation of flow and heat transfer for a $3 \mathrm{in}$. $(0.075 \mathrm{~m})$ diameter liquid encapsulant full float zone (LEFZ) growth of single-crystal GaAs was conducted using the finite-element method. Convective and conductive heat transfers, radiative heat transfer between diffuse surfaces and the Navier-Stokes equations for both melt and encapsulant as well as the interface position are all combined and solved simultaneously. The effect of the thickness of encapsulant, rotation rate of crystal and feed rod on the flow and heat transfer as well as on the growing and melting interface shape were investigated.
\end{abstract}

(c) 2004 Elsevier Ltd. All rights reserved.

Keywords: Liquid encapsulant full float zone; GaAs; Boron oxide; Finite-element method

\section{Introduction}

Liquid encapsulation float zone technique is a highly promising method for the growth of volatile materials such as gallium arsenide. By using liquid encapsulate the evaporation of the compounds can be prevented and Marangoni convection in the melt of growing material placed in low-gravity environment can be suppressed [1]. It was noted that the quality of the grown crystal is related to the thermal circumstance which somehow depends on the furnace geometry and the operation conditions, such as the thickness of encapsulant, crystal and feed rod rotation rate (or crucible rotation rate for LEC method) and so on.

Some numerical simulations for liquid encapsulant Czochralski growth of GaAs have been performed to illustrate the characteristics of the momentum and heat transfer. A prediction of the thermal field and the location of the growing interface was obtained by a

\footnotetext{
${ }^{*}$ Corresponding author. Tel.: +86-023-65415008; fax: +86023-65102473/71.

E-mail address: mwlizao@yahoo.com (M. Li).
}

global numerical simulation based on a conductiondominated model $[2,3]$. Thomas et al. extended the dynamic thermal-capillary model to simulate a lowpressure, liquid-encapsulant Czochralski system for the growth of GaAs [4]. The predicted crystal shape is in semiquantitative agreement with the experiment. The influence of the argon gas pressure on the heater power, convex curvature of the growing interface and the maximum thermal stress was studied by both laminar and turbulent models for the gas flow [5]. The effect of rotation rate of the crystal and crucible on the fluid flow, instability, heat transfer and interface shape was emphasized [6-9]. Two immiscible horizontal liquid layers: $\mathrm{B}_{2} \mathrm{O}_{3}$ (encapsulant) and $\mathrm{GaAs}$ (melt) were also chosen to study numerically the flow characteristics of thermocapillary convection [10]. Owing to the practical application of the LEFZ method for the growth of GaAs, Li et al. [11] investigated thermocapillary and buoyancy flow in co-axial liquid bridges with interface deformation. A GaAs single crystal of $20 \mathrm{~mm}$ diameter and $20 \mathrm{~mm}$ length has also been successfully grown under microgravity, high growth rate and dopant striations due to Marangoni convection were found [12]. From our knowledge, there is no research report for 
liquid encapsulant full float zone growth of gallium arsenide up till now. The characteristics of the momentum and heat transfer in such system differ from that in Czochralski system or in two layer liquid system. Some specific features may appear.

In the present paper, we extend our previous numerical investigation of LEC growth of GaAs to a liquid encapsulant full float zone growth including the growing and melting interface calculation. The effects of the thickness of encapsulant, crystal and feed rod rotation rates on the flow and temperature field as well as the growing and melting interface shape were discussed.

\section{Model formulation}

\subsection{Physical model and basic assumptions}

Schematic diagram adopted in the present analyses is shown in Fig. 1. Gallium arsenide melt with $7.5 \mathrm{~cm}$ diameter and $7.5 \mathrm{~cm}$ height is encapsulated by boron oxide with thickness of $b_{\mathrm{e}}$. The crystal and feed rod rotate in the opposite direction with $\omega_{\mathrm{s}}$ and $\omega_{\mathrm{f}}$, respectively. The heater and ambient temperature of each

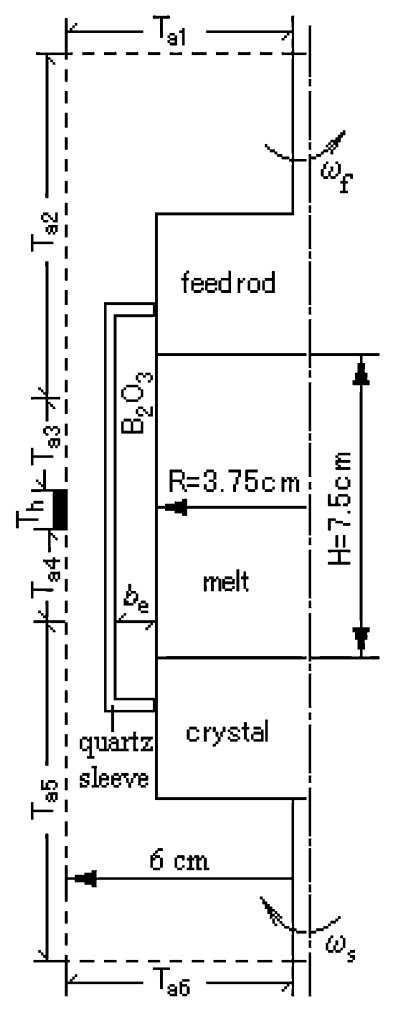

Fig. 1. Schematic diagram of a liquid encapsulated floating zone growth of GaAs. segment are given. The width of the heater is $1 \mathrm{~cm}$, and the widths of those segments for specified ambient temperature $T_{\mathrm{a} 1}, T_{\mathrm{a} 2}, T_{\mathrm{a} 3}, T_{\mathrm{a} 4}, T_{\mathrm{a} 5}, T_{\mathrm{a} 6}$ are $6,8.25,2.5,2.5$, 8.25 and $6 \mathrm{~cm}$, respectively. To simplify the problem, the following assumptions were introduced: (1) The system is in a pseudo-steady state and is axisymmetric. (2) The flow is laminar and both the GaAs melt and the boron oxide encapsulant are incompressible. (3) The melt/encapsulant interface is non-deformable. (4) Thermophysical properties of the melt are assumed to be constant except for the temperature dependencies of surface tension and the dynamic viscosity $\mu$ of boron oxide. (5) Crystal and the feed rod have the same thermophysical properties. (6) No subcooling exists at the growing interface and melting interfaces, i.e. the interface shapes coincide with the melting temperature isotherms. (7) Gravity is absent.

\subsection{Mathematical model}

\subsubsection{Governing equations}

Under the above assumptions, the governing equations for flow and temperature field are given as follows.

In the melt and encapsulant:

$$
\begin{aligned}
& \nabla \cdot \mathbf{v}_{\mathrm{i}}=0, \\
& \rho_{\mathrm{i}} \mathbf{v}_{\mathrm{i}} \cdot \nabla \mathbf{v}_{\mathrm{i}}=-\nabla p_{\mathrm{i}}-\nabla \cdot \tau_{\mathrm{i}}, \\
& \rho_{\mathrm{i}} c_{p \mathrm{i}} \mathbf{v}_{\mathrm{i}} \cdot \nabla T_{\mathrm{i}}=\lambda_{\mathrm{i}} \nabla \cdot \nabla T_{\mathrm{i}} .
\end{aligned}
$$

In the crystal:

$$
\rho_{\mathrm{s}} c_{p \mathrm{~s}} V_{\mathrm{s}} \mathbf{e}_{z} \cdot \nabla T_{\mathrm{s}}=\lambda_{\mathrm{s}} \nabla \cdot\left(\nabla T_{\mathrm{s}}\right) \text {. }
$$

In the feed rod:

$\rho_{\mathrm{f}} c_{p \mathrm{f}} V_{\mathrm{f}} \mathbf{e}_{z} \cdot \nabla T_{\mathrm{f}}=\lambda_{\mathrm{f}} \nabla \cdot\left(\nabla T_{\mathrm{f}}\right)$.

In other solid materials:

$\nabla \cdot\left(\nabla T_{\mathrm{j}}\right)=0$,

where $T, \mathbf{v}, p$, and $\tau$ are the temperature, velocity vector, pressure and stress tensor, respectively. Symbol $\rho$ stands for the density, $\lambda$ the thermal conductivity, $c_{p}$ the specific heat, $V_{\mathrm{s}}$ the crystal pulling rate and $V_{\mathrm{f}}$ the feed rod pulling rate, respectively. Subscripts $i, s, f$ and $j$ indicate GaAs melt ( $\mathrm{i}=1), \mathrm{B}_{2} \mathrm{O}_{3}$ encapsulant $(\mathrm{i}=\mathrm{e})$, crystal, feed rod and other materials, respectively. Vector $\mathbf{e}_{z}$ is a unit vector parallel to $z$-axis.

\subsubsection{Boundary conditions for the temperature field}

At the melt/encapsulant interface:

$-\lambda_{1} \mathbf{n} \cdot \nabla T_{1}=-\lambda_{\mathrm{e}} \mathbf{n} \cdot \nabla T_{\mathrm{e}}+q_{\mathrm{rad}, 1}$.

At the growing (melt/crystal) interface:

$\lambda_{1} n \cdot \nabla T_{1}-\lambda_{\mathrm{s}} n \cdot \nabla T_{\mathrm{s}}=\rho_{\mathrm{s}} V_{\mathrm{s}} \Delta H_{\mathrm{s}} n \cdot \mathbf{e}_{z}$,

$T_{1}=T_{\mathrm{s}}=T_{\mathrm{m}}$. 
At the melting (melt/feed rod) interface:

$$
\begin{aligned}
& \lambda_{\mathrm{l}} \mathbf{n} \cdot \nabla T_{\mathrm{l}}-\lambda_{\mathrm{f}} \mathbf{n} \cdot \nabla T_{\mathrm{f}}=-\rho_{\mathrm{f}} V_{\mathrm{f}} \Delta H_{\mathrm{f}} \mathbf{n} \cdot \mathbf{e}_{z}, \\
& T_{1}=T_{\mathrm{f}}=T_{\mathrm{m}} .
\end{aligned}
$$

At the encapsulated crystal side wall:

$-\lambda_{\mathrm{s}} \mathbf{n} \cdot \nabla T_{\mathrm{s}}=-\lambda_{\mathrm{e}} \mathbf{n} \cdot \nabla T_{\mathrm{e}}+q_{\mathrm{rad}, \mathrm{s}}$

At the encapsulated feed rod side wall:

$-\lambda_{\mathrm{f}} \mathbf{n} \cdot \nabla T_{\mathrm{f}}=-\lambda_{\mathrm{e}} \mathbf{n} \cdot \nabla T_{\mathrm{e}}+q_{\mathrm{rad}, \mathrm{f}}$.

At the encapsulated quartz sleeve surface:

$-\lambda_{\mathrm{s}} \mathbf{n} \cdot \nabla T_{\mathrm{s}}=-\lambda_{\mathrm{e}} \mathbf{n} \cdot \nabla T_{\mathrm{e}}+q_{\mathrm{rad}, \mathrm{q}}$.

At the exposed crystal side wall and top:

$-\lambda_{\mathrm{s}} \mathbf{n} \cdot \nabla T_{\mathrm{s}}=q_{\mathrm{rad}, \mathrm{s}}$.

At other exposed surfaces:

$-\lambda_{\mathrm{j}} \mathbf{n} \cdot \nabla T_{\mathrm{j}}=q_{\mathrm{rad}, \mathrm{j}}$.

In these equations, $q_{\mathrm{rad}, \mathrm{i}}$ is the net radiative heat flux per unit area on the surfaces and $\Delta H_{\mathrm{i}}(\mathrm{i}=\mathrm{s}, \mathrm{f})$ is the latent heat of fusion, $\mathbf{n}$ the unit normal vector of the interface element and $\varepsilon$ the emissivity.

\subsubsection{Boundary conditions for the flow field}

At the growing and the encapsulant/crystal interface:

$u_{\mathrm{i}}=v_{\mathrm{i}}=0, \quad w_{\mathrm{i}}=r \omega_{\mathrm{s}} \quad(\mathrm{i}=1$ or $\mathrm{f})$.

At the melting and encapsulant/feed interface:

$u_{\mathrm{i}}=v_{\mathrm{i}}=0, \quad w_{\mathrm{i}}=r \omega_{\mathrm{f}} \quad(\mathrm{i}=1$ or $\mathrm{f})$.

At the encapsulant/quartz sleeve surface:

$u_{\mathrm{e}}=v_{\mathrm{e}}=w_{\mathrm{e}}=0$.

At the melt/encapsulant interface:

$\mathbf{n} \cdot \mathbf{v}_{\mathrm{l}}=0, \quad \mathbf{n} \cdot \mathbf{v}_{\mathrm{e}}=0$,

$\tau_{1}: \mathbf{n t}-\tau_{\mathrm{e}}: \mathbf{n t}=\gamma_{\mathrm{T}} \nabla T_{1} \cdot \mathbf{e}_{z}$,

$\mathbf{t} \cdot \mathbf{v}_{1}-\mathbf{t} \cdot \mathbf{v}_{\mathrm{e}}=0$,

$\tau_{1}: \mathbf{n e}_{\theta}-\tau_{\mathrm{e}}: \mathbf{n e}_{\theta}=\gamma_{\mathrm{T}} \nabla T_{1} \cdot \mathbf{e}_{\theta}$,

$\mathbf{e}_{\theta} \cdot \mathbf{v}_{1}-\mathbf{e}_{\theta} \cdot \mathbf{v}_{\mathrm{e}}=0$.

At the axis:

$u_{1}=w_{1}=0$,

where $u, v$, and $w$ are the radial, axial and the azimuthal components of velocity, $\omega_{\mathrm{s}}$ and $\omega_{\mathrm{f}}$ are the angular rotation rates of the crystal and feed rod, respectively. Symbol $\gamma_{\mathrm{T}}$ denotes the temperature coefficient of interface tension, and $\mathbf{t}$ and $\mathbf{e}_{\theta}$ are the unit tangential and azimuthal vectors of each interface element, respectively.

Numerical procedure used here including the calculation of net radiative heat flux $q_{\mathrm{rad}, \mathrm{i}}$ and the determi- nation of the growing and melting interface shape are identical to our previous paper $[13,14]$. The related physical parameter and the treatment of the heat transfer in the semi-transparent boric oxide layer can be found in Ref. [14]. In the present calculation the total number of elements, nodal points and unknowns is 5662, 5856 and 19226, respectively. The sizes of the minimum elements in the melt are $\Delta r_{\min }=0.831 \mathrm{~mm}$, $\Delta z_{\min }=0.93 \mathrm{~mm}$. No obvious change in accuracy is found for the further fine mesh.

\section{Results and discussion}

In the calculation, the pulling rates were maintained at around $5 \mathrm{~mm} / \mathrm{h}$ within $\pm 1 \%$ for all cases by adjusting the heater and/or ambient temperature.

\subsection{Effect of encapsulant thickness}

In the absence of the crystal and feed rod rotation, the effect of the encapsulant thickness $b_{\mathrm{e}}$ on the flow and heat transfer is shown in Fig. 2(a)-(c). The flow in melt is characterized by two toroidal vortices, one is located in the upper half zone, whereas the other in the lower half zone. When $b_{\mathrm{e}}=0.2 \mathrm{~cm}$, the convection in the melt is very weak so that the heat transfer is conduction-dominated. The maximum temperature difference in the melt is quite large, $\mathrm{DT}=108 \mathrm{~K}$, compared with $\mathrm{DT}=67 \mathrm{~K}$ and DT $=46 \mathrm{~K}$ for the other two cases of $b_{\mathrm{e}}=1.0 \mathrm{~cm}$ and $b_{\mathrm{e}}=1.8 \mathrm{~cm}$ as shown in Table 1 . It can also be found from Fig. 3 that the temperature gradient along the growing interface is quite large. This large temperature gradient results in a large heat flux across the interface, i.e., $Q_{\mathrm{s}}=192 \mathrm{~W}$ (see Table 1). As a consequence, a concave (concave to the crystal) growing interface shape formed. In this case, high heater temperature of $T_{\mathrm{h}}=2427 \mathrm{~K}$ is needed. It is noticed that the value of $Q_{\mathrm{s}}$ in the case of $b_{\mathrm{e}}=1.8 \mathrm{~cm}$ is smaller than that in the case of $b_{\mathrm{e}}=1.0 \mathrm{~cm}$ even though the heater temperature is slightly higher for $b_{\mathrm{e}}=1.8 \mathrm{~cm}$ as depicted in Table 1. This is because that the flow in the $\mathrm{B}_{2} \mathrm{O}_{3}$ encapsulant is stronger and the area of the two sidewalls of the quartz sleeve is larger when $b_{\mathrm{e}}=1.8 \mathrm{~cm}$, more heat is rejected to the surrounding from the quartz sleeve, so the heat flow across the growing interface becomes less and a more convex (convex to melt) interface shape is observed. This is agree qualitatively with numerical results of Thomas [4] and Croll [12]. The melting interface exhibit similar feature as the growing interface, a concave (concave to the feed rod) melting interface will change into convex with increasing the encapsulant thickness, but the value of maximum deflection of the melting interface is not equal to that of growing interface (see 

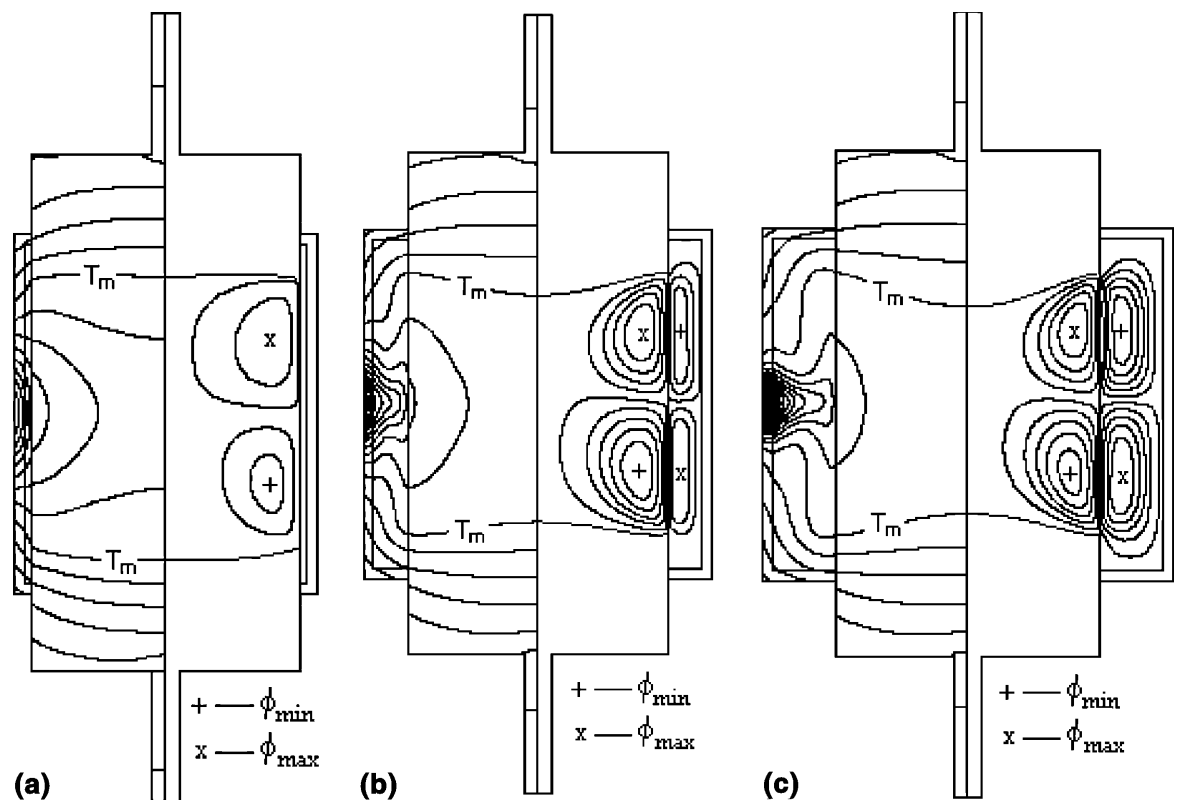

Fig. 2. Effect of encapsulant's thickness $\left(b_{\mathrm{e}}\right)$ on the flow and temperature distributions. The crystal and feed rod are motionless. Isotherms (left) at every $\Delta T=30 \mathrm{~K}$, and contours of stream function (right) at every $\Delta \phi_{1}=4.0 \times 10^{-8} \mathrm{~m}^{3} / \mathrm{s}, \Delta \phi_{\mathrm{e}}=4.0 \times 10^{-8} \mathrm{~m}^{3} / \mathrm{s}$. (a) $b_{\mathrm{e}}=0.2 \mathrm{~cm}$, (b) $b_{\mathrm{e}}=1.0 \mathrm{~cm}$, (c) $b_{\mathrm{e}}=1.8 \mathrm{~cm}$.

Table 1

Heater temperature and ambient temperature distribution and some representative parameters of the simulation results under different operating conditions

\begin{tabular}{|c|c|c|c|c|c|c|c|c|c|c|c|c|}
\hline & & $\begin{array}{l}T_{\mathrm{h}} \\
(\mathrm{K})\end{array}$ & $\begin{array}{l}T_{\mathrm{a} 1} \\
(\mathrm{~K})\end{array}$ & $\begin{array}{l}T_{\mathrm{a} 2} \\
(\mathrm{~K})\end{array}$ & $\begin{array}{l}T_{\mathrm{a} 3} \\
(\mathrm{~K})\end{array}$ & $\begin{array}{l}T_{\mathrm{a} 4} \\
(\mathrm{~K})\end{array}$ & $\begin{array}{l}T_{\mathrm{a} 5} \\
(\mathrm{~K})\end{array}$ & $\begin{array}{l}T_{\mathrm{a} 6} \\
(\mathrm{~K})\end{array}$ & $\begin{array}{l}Q_{\mathrm{s}} \\
(\mathrm{W})\end{array}$ & $\begin{array}{l}\text { DT } \\
(\mathrm{K})\end{array}$ & $\begin{array}{l}D_{\operatorname{maxs}} \\
(\mathrm{mm})\end{array}$ & $\begin{array}{l}D_{\operatorname{maxf}} \\
(\mathrm{mm})\end{array}$ \\
\hline \multirow{3}{*}{$\begin{array}{l}\text { Case I: } b_{\mathrm{e}}(\mathrm{cm}) \\
\qquad\left(\omega_{\mathrm{s}}=\omega_{\mathrm{f}}=0 \mathrm{rpm}\right)\end{array}$} & 0.2 & 2427 & 1305 & 1382 & 1458 & 1428 & 1353 & 1278 & 192 & 108 & -3.8 & -1.5 \\
\hline & 1.0 & 2369 & 1301 & 1378 & 1454 & 1420 & 1345 & 1270 & 161 & 67 & 3.3 & 6.2 \\
\hline & 1.8 & 2378 & 1302 & 1379 & 1456 & 1418 & 1343 & 1269 & 139 & 46 & 6.05 & 9.56 \\
\hline \multirow{3}{*}{$\begin{array}{c}\text { Case II: } \omega_{\mathrm{s}}(\mathrm{rpm}) \\
\left(b_{\mathrm{e}}=1.0 \mathrm{~cm}\right. \\
\left.\omega_{\mathrm{f}}=3 \mathrm{rpm}\right)\end{array}$} & 1 & 2380 & 1313 & 1390 & 1468 & 1399 & 1326 & 1252 & 183 & 77 & -0.57 & -3.13 \\
\hline & 3 & 2378 & 1302 & 1379 & 1456 & 1415 & 1341 & 1266 & 184 & 80 & -6.45 & -4.33 \\
\hline & 5 & 2380 & 1299 & 1375 & 1451 & 1417 & 1342 & 1268 & 193 & 79 & -8.5 & -3.5 \\
\hline \multirow{2}{*}{$\begin{array}{l}\text { Case III: } \omega_{\mathrm{f}}(\mathrm{rpm}) \\
\quad\left(b_{\mathrm{e}}=1.0 \mathrm{~cm}\right. \\
\left.\omega_{\mathrm{s}}=3 \mathrm{rpm}\right)\end{array}$} & 1 & 2381 & 1287 & 1363 & 1438 & 1427 & 1352 & 1277 & 175 & 77 & -6.03 & 2.33 \\
\hline & 5 & 2378 & 1304 & 1380 & 1457 & 1413 & 1338 & 1264 & 185 & 79 & -5.84 & -5.43 \\
\hline
\end{tabular}

$Q_{\mathrm{s}}$ : total heat flow across the growing interface.

DT: maximum temperature difference in the melt. DT $=T_{\max }-T_{\mathrm{m}}$, here $T_{\max }$ stands for the maximum temperature in the melt. $D_{\operatorname{maxs}}$ : maximum deflection of the growing interface. The symbol minus "-" means that the interface is concave (to the crystal). $D_{\text {maxf }}$ : maximum deflection of the melting interface. The symbol minus "-" means that the interface is concave (to the feed rod).

Fig. 2(b) and (c) and also see Table 1). From the analysis above, it is clear that not only the melt convection itself, but also the flow of the $\mathrm{B}_{2} \mathrm{O}_{3}$ encapsulant and the geometry configuration of the encapsulant have a significant impact on the heat transfer and the growing and melting interface shapes to a great extent.

\subsection{Effect of crystal and feed rod rotation}

Crystal and feed rod rotation has a considerable effect on the flow pattern and heat transfer as shown in Figs. 4(a)-(c) and 5(a) and (b). The forced convection cells driven by crystal and feed rod rotation become dominate 




Fig. 3. Temperature gradient along the growing interface under different thickness $b_{\mathrm{e}}\left(\omega_{\mathrm{s}}=0 \mathrm{rpm}, \omega_{\mathrm{f}}=0 \mathrm{rpm}\right)$.

and occupy the main region of the melt. The flow pattern in the melt depends upon the crystal and feed rod rotation rate and their ratio. When the crystal and feed rod rotation rate is matchable, i.e. the absolute value of the ratio $\omega_{\mathrm{s}} / \omega_{\mathrm{f}}$ is approximately equal to unity, four-cell type flow in the melt appears as shown in Fig. 4(b), where two forced convection cells and two thermocapillary convection cells co-exist, which are confined to their respective half-zone. The thermocapillary convection cells are extruded to a narrow region in the vicinity of the melt/encapsulant interface. When the absolute value of the ratio $\omega_{\mathrm{s}} / \omega_{\mathrm{f}}$ is apart from unity to some degree, the forced convection cells may penetrate the whole floatzone and merge one of the thermocapillary convection cell to form a combined bigger one see Figs. 4(a) and (c) and 5(a) and (b). The remaining thermocapillary con-
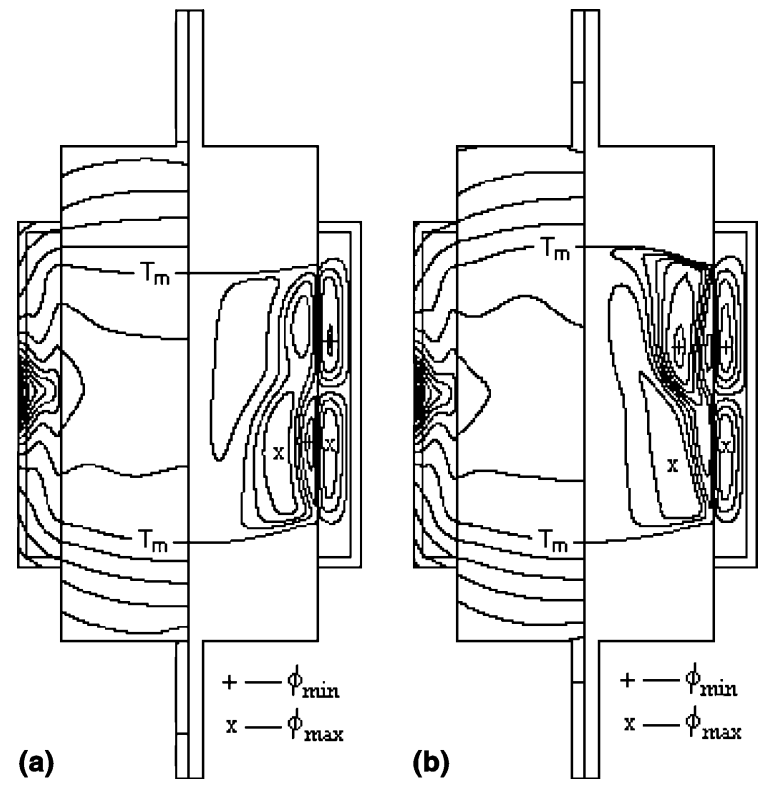

Fig. 5. Effect of feed rod rotation rate $\left(\omega_{\mathrm{f}}\right)$ on the flow and temperature distributions. $\omega_{\mathrm{s}}=3 \mathrm{rpm}, b_{\mathrm{e}}=1.0 \mathrm{~cm}$. Isotherms (left) at every $\Delta T=30 \mathrm{~K}$, and contours of stream function (right) at every $\Delta \phi_{1}=4.0 \times 10^{-8} \mathrm{~m}^{3} / \mathrm{s}, \Delta \phi_{\mathrm{e}}=4.0 \times 10^{-8} \mathrm{~m}^{3} / \mathrm{s}$. (a) $\omega_{\mathrm{f}}=1 \mathrm{rpm}$, (b) $\omega_{\mathrm{f}}=3 \mathrm{rpm}$.

vection cell will never disappear, although it is restricted to the very narrow region adjacent to the melt/encapsulant interface.
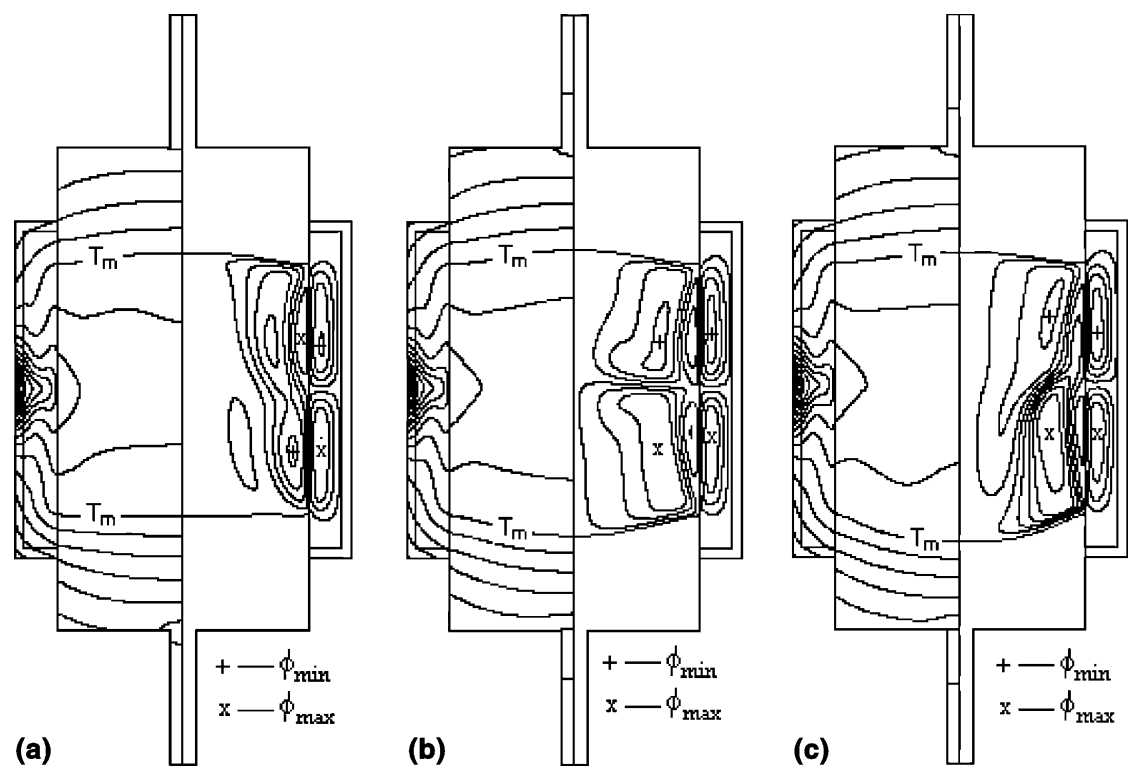

Fig. 4. Effect of crystal rotation rate $\left(\omega_{\mathrm{s}}\right)$ on the flow and temperature distributions. $\omega_{\mathrm{f}}=3 \mathrm{rpm}, b_{\mathrm{e}}=1.0 \mathrm{~cm}$. Isotherms (left) at every $\Delta T=30 \mathrm{~K}$, and contours of stream function (right) at every $\Delta \phi_{1}=4.0 \times 10^{-8} \mathrm{~m}^{3} / \mathrm{s}, \Delta \phi_{\mathrm{e}}=4.0 \times 10^{-8} \mathrm{~m}^{3} / \mathrm{s}$. (a) $\omega_{\mathrm{s}}=1 \mathrm{rpm},(\mathrm{b}) \omega_{\mathrm{s}}=3$ $\mathrm{rpm}$, (c) $\omega_{\mathrm{s}}=5 \mathrm{rpm}$. 


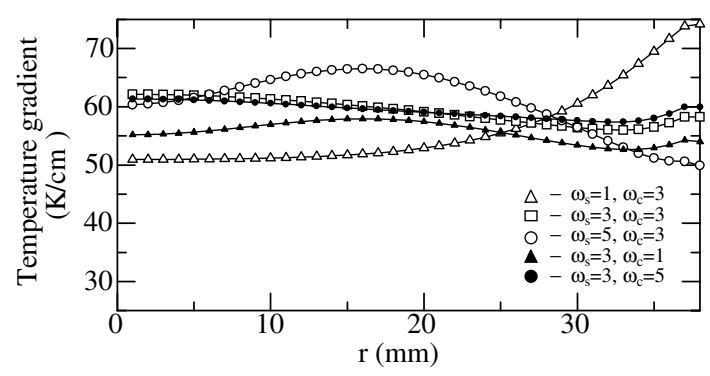

Fig. 6. Temperature gradient along the growing interface under different crystal and feed rod rotation rate $\left(b_{\mathrm{e}}=1.0 \mathrm{~cm}\right)$.

By a detail comparison and analysis of the flow and temperature field for the three different crystal rotation rates given by Fig. 4(a)-(c) one can find that the growing interface shape depends on the flow pattern to a great extent. For the small crystal rotation rate of $\omega_{\mathrm{s}}=1 \mathrm{rpm}$, the fluid heated by the melt/encapsulate interface is carried to the periphery above the growing interface by the combined cell, the center and medium region (for a half section the dimensionless radius $r$ is approximately in the range of $0-0.3$ and $0.3-0.7$, respectively) almost not be influenced by the melt convection, therefore the temperature gradient in the edge is larger in order to take away more heat to the surrounding (see Fig. 6). This heat transport feature causes the growing interface more flat. On the contrary, for the higher crystal rotation rate $\left(\omega_{\mathrm{s}}=5 \mathrm{rpm}\right.$, see Fig. 4(c)), the crystal rotation driving flow cell combined with the upper thermocapillary convection cell enhances the convective heat transfer in the medium region above the growing interface so that the temperature gradient in that region is higher than that in the center and edge region, as exhibited in Fig. 6. In this situation the growing interface shape becomes more concave (to the crystal) [4]. The melting interface does not change so much with the increase of crystal rotation rate. On the other hand, from the maximum deflection of the interface given in Table 1, the influence of feed rod rotation rate on the melting interface shape is significant, but on the growing interface is negligible. The data in Table 1 also show that the heater and ambient temperature needed to be adjusted (or optimized) for a specific growth condition (i.e. for a given pulling speed, furnace configuration and rotation rate of crystal and feed rod) as indicated in Ref. [15].

\section{Conclusions}

Taking the growing and melting interface shape into account, the characteristics of flow and heat transfer in LEFZ growth of CaAs was studied numerically for the first time by using a full float zone simulation code. The results indicate that:
1. The heat transfer and the interface shape are associated with not only the melt convection, but also the flow of encapsulant and its geometry configuration. When increase the thickness of the encapsulant, the interface shape will become more convex.

2. Crystal and feed rod rotation rate has a remarkable effect on the flow pattern and heat transfer. Complex multi-cell flow pattern may appear in the melt when introducing the rotation, which gives a significant influence on the interface shape. When increasing the crystal rotation rate from 1 to $5 \mathrm{rpm}$, the growing interface shape will change from slight concave (almost flat) to notable concave, whereas the melting interface does not change so much. On the contrary the feed rod rotation rate have a remarkable impact on melting interface shape, but the growing interface remains almost a constant deflection even though the feed rot rotation rate change from $1 \mathrm{rpm}$ to $5 \mathrm{rpm}$ for a fixed crystal rotation rate of $3 \mathrm{rpm}$.

3. Different from the traditional LEC growth, the full float zone modeling and simulation involves not only the determination of growing interface but also the determination of melting interface. For a given thickness of encapsulant and crystal and feed rot rotation rate, the heater and ambient temperature needed to be adjusted to suit for the specified pull rate.

In principle, the melt/encapsulant interface is not flat and non-deformable even though under microgravity circumstance, the assumption of non-deformable should be released in the further simulation.

\section{Acknowledgements}

This work was supported by NSFC with grant no. 50376078 and by the Excellent Young Teachers Program of MOE (EYTP), PRC [2002]40.

\section{References}

[1] M.W. Li, D.L. Zeng, The effect of liquid encapsulation on the Marangoni convection in a liquid column under microgravity condition, Int. J. Heat Mass Transfer 39 (17) (1996) 3725-3732.

[2] F. Dupret, P. Nicodeme, Y. Ryckmans, P. Wouters, M.J. Crochet, Numerical method for reducing stress level in GaAs crystal, J. Cryst. Growth 97 (1989) 162172.

[3] F. Dupret, P. Nicodeme, Y. Ryckmans, P. Wouters, M.J. Crochet, Global modeling of heat transfer in crystal growth furnaces, Int. J. Heat Mass Transfer 33 (9) (1990) 1849-1871.

[4] P.D. Thomas, J.J. Derby, L.J. Atherton, R.A. Brown, Dynamics of liquid-encapsulanted Czochralski growth of 
gallium arsenide: comparing model with experiment, J. Cryst. Growth 96 (1989) 135-152.

[5] J. Fainberg, H.-J. Leister, G. Muller, Numerical simulation of the LEC-growth of GaAs crystals with account of highpressure gas convection, J. Cryst. Growth 180 (1997) 517523.

[6] M.E. Salcudean, P. Sabhapathy, F. Weinberg, Numerical study of free and forced convection in the growth of GaAs, J. Cryst. Growth 94 (1989) 522-526.

[7] X. Geng, X.B. Wu, Z.Y. Guo, Numerical simulation of combined flow in Czochralski crystal growth, J. Cryst. Growth 179 (1997) 309-319.

[8] V.I. Polezhaev, O.A. Bessonov, N.V. Nikitin, S.A. Nikitin, Convective interaction and instabilities in GaAs Czochralski model, J. Cryst. Growth 230 (2001) 40-47.

[9] U. Rehse, W. Miller, Ch. Frank, P. Rudolph, M. Neubert, A numerical investigation of the effects of iso- and counterrotation on the shape of the $\mathrm{VCz}$ growth interface, J. Cryst. Growth 230 (2001) 143-147.
[10] Q.S. Liu, B. Roux, M.G. Velarde, Thermocapillary convection in two-layer systems, Int. J. Heat Mass Transfer 41 (11) (1998) 1499-1511.

[11] J. Li, J. Sun, Z. Saghir, Buoyant and thermocapillary flow in liquid encapsulated float zone, J. Cryst. Growth 131 (1993) 83-96.

[12] A. Croll, M. Schweizer, A. Tegetmeier, K.W. Benz, Floating zone growth of GaAs, J. Cryst. Growth 166 (1996) 239-244.

[13] M.W. Li, Y.R. Li, N. Imaishi, T. Tsukada, Global simulation of a silicon Czochralski furnace, J. Cryst. Growth 234 (2002) 32-46.

[14] M.W. Li, W.R. Hu, N.H. Chen, D.L. Zeng, Z.M. Tang, Numerical analysis of LEC growth of GaAs with an axial magnetic field, Int. J. Heat Mass Transfer 45 (2002) 28432851.

[15] K. Lin, P. Dold, Radiative heat transfer in a resistance heated floating zone furnace: a numerical study with FIDAP, Cryst. Res. Technol. 36 (2001) 629-639. 